\title{
Revascularization Strategies in Patients Presenting With ST-Elevation Myocardial Infarction and Multivessel Coronary Disease
}

\author{
Maria Natalia Tovar Forero, MD, Paola Scarparo, MD, Wijnand den Dekker, MD, PhD, \\ Matthew Balbi, MD, Kaneshka Masdjedi, MD, Laurens van Zandvoort, BS, Isabella Kardys, MD, PhD, \\ Koen Ameloot, MD, Joost Daemen, MD, PhD, Miguel Lemmert, MD, PhD, Jeroen Wilschut, MD, \\ Peter de Jaegere, MD, PhD, Felix Zijlstra, MD, PhD, Nicolas Van Mieghem, MD, PhD, and \\ Roberto Diletti, MD, PhD*
}

\begin{abstract}
The optimal revascularization strategy for residual coronary stenosis following primary percutaneous coronary intervention in patients with ST-segment elevation myocardial infarction (STEMI) and multivessel disease (MVD) remains controversial. This is a retrospective single-centre study including patients with STEMI and MVD. Based on the revascularization strategy, 3 groups were identified: (1) culprit only (CO), (2) ad hoc multivessel revascularization (MVR), and (3) staged MVR. Clinical outcomes were compared in terms of major adverse cardiac events (MACE), a composite of cardiac death, any myocardial infarction, and any unplanned revascularization at a long-term follow-up. A total of 958 patients were evaluated, 489 in the $\mathrm{CO}, 254$ in the ad hoc, and 215 in the staged group. In the staged group, $65.6 \%$ of the patients received planned percutaneous coronary intervention, $9.7 \%$ coronary artery bypass grafting, $8.4 \%$ no further intervention after lesion reassessment, and in $16.3 \%$ an event occurred before the planned procedure. At 1,095 days, MACE was $36.1 \%, 16.7 \%$, and $31 \%$ for $\mathrm{CO}$, ad hoc, and staged groups, respectively. A MVR strategy was associated with lower rate of all-cause death compared with $\mathrm{CO}$ (HR $0.50 ; 95 \% \mathrm{CI}[0.31$ to 0.80$] ; \mathrm{p}=0.004)$. Complete revascularization reduced the rate of MACE (HR 0.30 [0.21 to 0.43] p < 0.001) compared with incomplete revascularization. Ad hoc MVR had lower rate of MACE compared with staged MVR (HR 0.61 [0.39 to 0.96] $p=0.032$ ) mainly driven by less unplanned revascularizations.

In conclusion, in patients with STEMI and MVD, complete revascularization reduced the risk of MACE. Ad hoc MVR appeared a reasonable strategy with lower contrast and stent usage and costs. $\bigcirc 2020$ Elsevier Inc. All rights reserved. (Am J Cardiol 2020;00:1-6)
\end{abstract}

Primary percutaneous coronary intervention (PCI) is the gold standard for the treatment of patients with an acute ST-segment elevation myocardial infarction (STEMI), ${ }^{1-3}$ and up to $52 \%$ of those cases present with multivessel disease (MVD) increasing the risk of future cardiovascular events. ${ }^{4}$ The management of the nonculprit lesions, however, remains controversial. ${ }^{5}$ Recent randomized trials showed improved clinical outcomes in patients who underwent complete revascularization. PCI of noninfarct related arteries (non-IRA) was performed either during the index procedure, ${ }^{6,7}$ in a staged procedure during hospital admission, ${ }^{8,9}$ or mixing the 2 strategies. ${ }^{10}$ Based on these data, the current European Guidelines report that revascularization of non-IRA lesions should be considered in STEMI patients with MVD. ${ }^{11}$ However, the optimal timing of

Department of Cardiology, Erasmus University Medical Centre, Rotterdam, The Netherlands. Manuscript received October 10, 2019; revised manuscript received and accepted January 30, 2020.

Funding disclosures: No funding institutions had any involvement in data collection or analysis and in the writing of the report.

See page 5 for disclosure information.

*Corresponding author: Tel: 31-(0)10-7035260; fax: 31-(0)107035254.

E-mail address: r.diletti@erasmusmc.nl (R. Diletti). revascularization (i.e., immediate vs staged) has not been adequately investigated. Therefore, the purpose of the present study is to evaluate the impact of the different revascularization strategies on clinical outcome in patients presenting with STEMI and MVD.

\section{Methods}

All consecutive patients with MVD (defined as significant stenosis $(>50 \%)$ in at least 1 nonculprit epicardial coronary artery ( $>2 \mathrm{~mm})$ as assessed by visual estimation), who underwent primary PCI between January 2010 and March 2017 were eligible for the present study. Out of hospital cardiac arrest, cardiogenic shock, presence of chronic total occlusions, previous coronary artery bypass grafting (CABG), ambiguity about the culprit lesion and unknown final revascularization status (no information regarding the staged procedure) were excluded.

According to the revascularization strategy adopted by the operator at the index PCI, the population was divided into 3 groups: (1) Culprit only (CO): defined as PCI of the culprit artery only followed by medical treatment. (2) Ad hoc multivessel revascularization (MVR): defined as PCI of the IRA and at least one non-IRA at the index procedure followed by 
medical treatment with no further planned revascularization. (3) Staged MVR: defined as the treatment of the IRA \pm nonIRA at the index procedure followed by planned revascularization of the remaining lesions within 6 weeks. Based on approach and completeness of revascularization 3 specific comparisons were predefined: $\mathrm{CO}$ revascularization vs MVR, complete vs incomplete revascularization, and ad hoc vs staged MVR. Major adverse cardiac events (MACE) were defined as a composite of cardiac death, any myocardial infarction (MI) (Q- or non-Q-wave) and any unplanned revascularization (either $\mathrm{PCI}$ or $\mathrm{CABG}$ ).

Overall death was defined as all-cause mortality. All deaths were considered cardiac unless an undisputed noncardiac cause was identified. ${ }^{12}$ MI was defined as the increased and/or decreased of cardiac-specific troponin values with at least 1 value above the 99th percentile of the upper reference limit and with the presence of ischemic symptoms, new ischemic electrocardiographic changes, development of pathological Q waves, wall motion abnormalities in a pattern consistent with an ischemic aetiology, and/or presence of intracoronary thrombus. ${ }^{13}$ Any unplanned revascularization was defined as any PCI or CABG procedure performed during the follow-up in target and/or nontarget vessels, outside of the initial intended revascularization strategy; this definition included any unplanned revascularization occurring after the index PCI and before the staged revascularization date for the staged cohort. Significant coronary lesions were defined as a lumen diameter stenosis $\geq 50 \%$ as assessed by visual estimation or quantitative coronary analysis. Complete revascularization was considered when all significant coronary lesions suitable for revascularization as per operator's discretion were treated as planned and had a final Thrombolysis in myocardial infarction (TIMI) flow grade 2 or 3 with residual stenosis $<30 \%$, otherwise it was considered as incomplete.

Survival data for all patients were obtained from municipal civil registries. A health questionnaire was subsequently sent to all living patients with specific questions on readmission and major adverse cardiac events. For patients who had an adverse event at another center, general practitioners, referring cardiologists, and patients were contacted as necessary for additional information.

Categorical data are presented as counts and percent, and the differences between groups were tested by the chi-square test or Fisher's exact test when appropriate. Continuous data are presented as median and interquartile range (IQR; 25th to 75 th percentile), and the differences between groups tested by the Kruskal-Wallis test. Pairwise comparisons were performed to identify significant differences among groups. The Kaplan-Meier method was used to plot event-free survival curves. Differences were evaluated by the log-rank test. Variables associated with clinical outcomes were identified using univariate Cox proportional-hazards models. Variables with a $p$ value $<0.05$ were introduced into a multivariate Cox proportional-hazards model to adjust for the effect of potential confounders. Proportional hazards assumptions were tested by $\log$-minus-log survival probability plots and by fitting time-dependent covariates. Extended Cox regression including the interaction between group treatment and time was performed when proportional hazards assumptions were not met. Data are presented as hazard ratios (HRs) with 95\% confidence intervals $[95 \% \mathrm{CI}]$. Overall, tests were 2-tailed and a $\mathrm{p}$ value $<0.05$ was considered statistically significant and the Bonferroni correction was applied in cases where pairwise comparisons were performed. SPSS software version 24.0 for Windows (SPSS, Inc., Chicago) was used to perform all analyses.

\section{Results}

From January 2010 to March 2017 a total of 1,473 STEMI patients with MVD were identified. Out of the total population, 958 patients met the inclusion and none of the exclusion criteria. $\mathrm{CO}$ revascularization was performed in 489 cases and 469 patients underwent MVR. Ad hoc revascularization of non-IRA arteries was performed in 254 patients and a planned staged revascularization of non-IRA arteries was scheduled for 215 patients. Supplementary material Figure 1. Median follow-up was 1116 days (IQR 226 to 2151 days).

Overall, the staged cohort was younger compared with the other 2 revascularization strategies. Other baseline demographics were well balanced among groups. Baseline characteristics are summarized in Table 1 .

The staged group had more frequently 3 vessel disease and or left main disease. The right coronary artery was more often the IRA (46.9\% of the cases) with a significantly greater proportion in the $\mathrm{CO}$ group, and the newer P2Y12 inhibitors (Prasugrel or Ticagrelor) were more often prescribed to patients who underwent MVR. Although no differences were found in IRA complications, a significantly higher rate of non-IRA complications (dissections, distal embolization, slow flow and/or no-reflow, perforation, sudden thrombosis), was found in the ad hoc MVR strategy. In contrast, the staged group received more number of stents and overall (index + staged procedure) a larger amount of contrast medium. Complete revascularization was achieved in 420 patients. Procedural characteristics are tabulated in Table 2.

Of 215 patients with a planned staged procedure, the staged revascularization was performed in 162 patients (PCI in 141 cases and CABG in 21 cases) at a median of 10.5 days (IQR 4 to 29 days) postindex PCI; in 18 patients ( $8.4 \%$ of the cohort) the non-IRA treatment was aborted after FFR-reassessment of lesion severity, and 35 patients ( $16.3 \%$ of the cohort) required premature revascularization for new STEMI (2 cases), non-ST segment elevation acute coronary syndromes (20 cases), residual angina (11 cases), and decompensated acute heart failure ( 2 cases); these 35 patients were considered as incomplete revascularization within the staged cohort, and the premature revascularization as an event.

The cumulative incidence of MACE at 1,095 days was $36.1 \%, 31 \%$, and $16.7 \%$ in the CO, staged and ad hoc cohorts, (log-rank test for $\mathrm{CO}$ vs ad hoc $\mathrm{p}<0.001$, $\mathrm{CO}$ vs staged $\mathrm{p}=0.343$, and ad hoc vs staged $\mathrm{p}=0.002$. Figure 1 ; Supplementary material Table 1).

Table 3 shows the risk of outcomes among revascularization strategies. When comparing MVR versus $\mathrm{CO}$ no significant difference was found in MACE (HR 0.81; $95 \%$ CI $[0.59$ to 1.10$] ; \mathrm{p}=0.184$ Supplementary material Figure 2-A) or any of the individual components of MACE; however, a significantly lower risk of overall 
Table 1

Baseline characteristics

\begin{tabular}{|c|c|c|c|c|}
\hline Variable & $\begin{array}{l}\text { Culprit only } \\
(\mathrm{n}=489)\end{array}$ & $\begin{array}{l}\text { Ad hoc multivessel } \\
\text { revascularization } \\
\quad(\mathrm{n}=254)\end{array}$ & $\begin{array}{l}\text { Staged multivessel } \\
\text { revascularization } \\
\quad(n=215)\end{array}$ & $\mathrm{p}$ value \\
\hline Age (Years) & $66(56-76)$ & $66(55-74)$ & $62(54-71)$ & 0.012 \\
\hline Dyslipidemia & $161 / 488(32.9 \%)$ & $84 / 254(33.1 \%)$ & $67 / 215(31.2 \%)$ & 0.87 \\
\hline Hypertension & $218 / 488(44.7 \%)$ & $101 / 254(39.8 \%)$ & $87 / 215(40.5 \%)$ & 0.35 \\
\hline Diabetes mellitus & $82 / 488(16.8 \%)$ & $32 / 254(12.6 \%)$ & $25 / 215(11.6 \%)$ & 0.11 \\
\hline Peripheral vascular disease & $23 / 488(4.7 \%)$ & $6 / 254(2.4 \%)$ & $4 / 215(1.9 \%)$ & 0.08 \\
\hline Previous myocardial infarction & $47 / 488(9.6 \%)$ & $20 / 254(7.9 \%)$ & $14 / 215(6.5 \%)$ & 0.36 \\
\hline Previous percutaneous coronary intervention & $56 / 488(11.5 \%)$ & $27 / 254(10.6 \%)$ & $12 / 215(5.6 \%)$ & 0.05 \\
\hline Previous cerebrovascular accident/ischemic transitory attack & $31 / 488(6.4 \%)$ & $8 / 254(3.1 \%)$ & $12 / 215(5.5 \%)$ & 0.18 \\
\hline Current smoking & $190 / 488(39.1 \%)$ & $100 / 254(39.4 \%)$ & $82 / 215(37.8 \%)$ & 0.96 \\
\hline Basal creatinine $(\mu \mathrm{mol} / \mathrm{L})$ & $81(69-94)$ & $81.5(69-96)$ & $81(69-94)$ & 0.88 \\
\hline
\end{tabular}

Dyslipidemia was defined as total cholesterol $>5.2 \mathrm{mmol} / \mathrm{L}, \mathrm{LDL}-\mathrm{C} \geq 3.4 \mathrm{mmol} / \mathrm{L}$ or triglycerides $\geq 1.7 \mathrm{mmol} / \mathrm{L}$. Hypertension was defined as blood pressure $\geq 140 / 90 \mathrm{~mm} \mathrm{Hg}$ (millimeters of mercury). Categorical data are presented as counts and \% and tested by chi-square test. Continuous data are presented as median and interquartile range (IQR; 25 th to 75 th percentile) and tested by Kruskal-Wallis test when appropriate.

Table 2

Procedural characteristics

\begin{tabular}{|c|c|c|c|c|}
\hline Variable & $\begin{array}{l}\text { Culprit only } \\
(\mathrm{n}=489)\end{array}$ & $\begin{array}{l}\text { Ad hoc multivessel } \\
\text { revascularization } \\
\quad(\mathrm{n}=254)\end{array}$ & $\begin{array}{l}\text { Staged multivessel } \\
\text { revascularization } \\
\quad(\mathrm{n}=215)\end{array}$ & $\mathrm{p}$ value \\
\hline Three vessel coronary disease & $133 / 489(27.2 \%)$ & $55 / 254(21.7 \%)$ & $85 / 215(39.5 \%)$ & $<0.001$ \\
\hline \multicolumn{5}{|l|}{ Infarct-related artery } \\
\hline Left main & $2 / 489(0.4 \%)$ & $3 / 254(1.2 \%)$ & $0 / 215(0 \%)$ & 0.232 \\
\hline Left anterior descending & $161 / 489(32.9 \%)$ & $88 / 254(34.6 \%)$ & $61 / 215(28.4 \%)$ & 0.32 \\
\hline Infarct -related artery Thrombolysis in myocardial infarction pre 0-1 & $299 / 489(61.1 \%)$ & $142 / 254(55.9 \%)$ & $142 / 215(66 \%)$ & 0.08 \\
\hline Infarct -related artery Thrombolysis in myocardial infarction post $2-3$ & $483 / 489(98.8 \%)$ & $253 / 254(99.6 \%)$ & $215 / 215(100 \%)$ & 0.16 \\
\hline Infarct-related artery treatment type & & & & 0.068 \\
\hline Stenting & $474 / 489(96.9 \%)$ & $254 / 254(100 \%)$ & $211 / 215(98.1 \%)$ & \\
\hline Plain old balloon angioplasty & $13 / 489(2.7 \%)$ & $0 / 254(0 \%)$ & $4 / 215(1.9 \%)$ & \\
\hline Thromboaspiration only & $2 / 489(0.4 \%)$ & $0 / 254(0 \%)$ & $0 / 215(0 \%)$ & \\
\hline Index intracoronary imaging & $67 / 489(13.7 \%)$ & $33 / 254(13 \%)$ & $37 / 215(17.2 \%)$ & 0.37 \\
\hline Index fractional flow reserve assessment & $11 / 489(2.2 \%)$ & $12 / 254(4.7 \%)$ & $6 / 215(2.8 \%)$ & 0.17 \\
\hline Index drug-eluting stent & $461 / 474(97.3 \%)$ & $253 / 254(99.6 \%)$ & $210 / 212(96.7 \%)$ & 0.06 \\
\hline Index stent number & $1(1-2)$ & $2(2-3)$ & $1(1.2-2)$ & $<0.001$ \\
\hline Index stent length (mm) & $28(18-40)$ & $48.5(36-66.2)$ & $26(18-36)$ & $<0.001$ \\
\hline Total stent number (index+/-staged) & $1(1-2)$ & $2(2-3)$ & $2(1.2-4)$ & $<0.001$ \\
\hline Total stent length ( $\mathrm{mm})($ index $+/$-staged $)$ & $28(18-40)$ & $48.5(36-66.2)$ & $50(30-76)$ & $<0.001$ \\
\hline Index contrast $(\mathrm{ml})$ & $150(110-200)$ & $170(140-220)$ & $150(120-200)$ & $<0.001$ \\
\hline Total contrast (ml) (index+/-staged) & $150(110-200)$ & $170(140-220)$ & $260(200-340)$ & $<0.001$ \\
\hline Complete revascularization & $0 / 489(0)$ & $243 / 254(95.7)$ & $177 / 215(82.3)$ & $<0.001$ \\
\hline Aspirin prescribed & $488 / 488(99.8 \%)$ & $253 / 254(99.6 \%)$ & $215 / 215(100 \%)$ & 0.64 \\
\hline \multicolumn{5}{|l|}{ P2Y12 Inhibitor prescribed } \\
\hline
\end{tabular}

Categorical data are presented as counts and \% and tested by chi-square test or Fisher's exact test when appropriate. Continuous data are presented as median and Inter-Quartile Range (IQR; 25th to 75th) and tested by Kruskal-Wallis test when appropriate. 


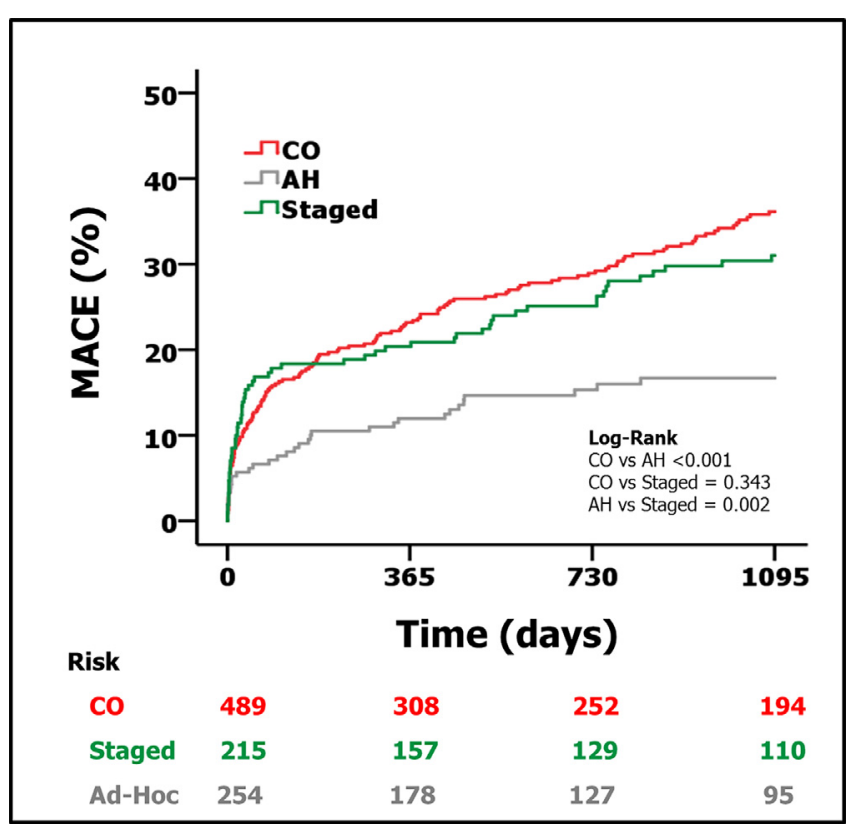

Figure 1. Cumulative incidence of major adverse cardiac events (MACE) at 1095 days. Ad hoc multivessel revascularization (AH). Culprit only (CO); Major Adverse Cardiac Events (MACE); Multivessel revascularization (MVR).

death was present in patients receiving MVR (HR 0.50; 95\% CI [0.31 to 0.80]; $\mathrm{p}=0.004)$. Complete revascularization appeared protective for MACE (HR 0.30; 95\%CI [0.21 to 0.43 ]; $\mathrm{p}<0.001)$ mainly driven by a significant reduction in MI (HR 0.47; 95\%CI [0.26 to 0.86]; $\mathrm{p}=0.014)$ and unplanned revascularizations (HR 0.15; 95\% CI [0.08 to 0.27]; $\mathrm{p}<0.001$ ).

In a sub-analysis comparing both MVR strategies, the ad hoc cohort showed a significant lower risk of MACE (HR $0.61 ; 95 \% \mathrm{CI}[0.39$ to 0.96$] ; \mathrm{p}=0.032)$ and unplanned revascularizations (HR 0.39; 95\% CI [0.22 to 0.67]; $\mathrm{p}<0.001$. No strategy impacted significantly the risk of future overall death, cardiac death or MI. Supplementary material Figure 2-B.

\section{Discussion}

Our main findings are: (1) Ad hoc MVR was associated with lower MACE compared with CO or staged strategies. (2) Less unplanned revascularizations occurred in the ad hoc MVR compared with staged MVR. (3) Complete revascularization was associated with lower MACE compared with incomplete revascularization. (4) Intracoronary imaging assessment or coronary physiology redefines the significance of non-IRA. In line with previous RCTs, our study confirmed a higher incidence of adverse events in patients receiving culprit only revascularization compared with patients treated with a MVR approach. ${ }^{6-10}$

Among the MVR strategies, ad hoc MVR appeared to be strongly related to a reduced early risk of unplanned revascularizations; of note, $16.3 \%$ of the staged cohort required unplanned revascularization before the staged intervention. A similar trend was found in the population who underwent complete revascularization at the index procedure as compared with those having a staged procedure

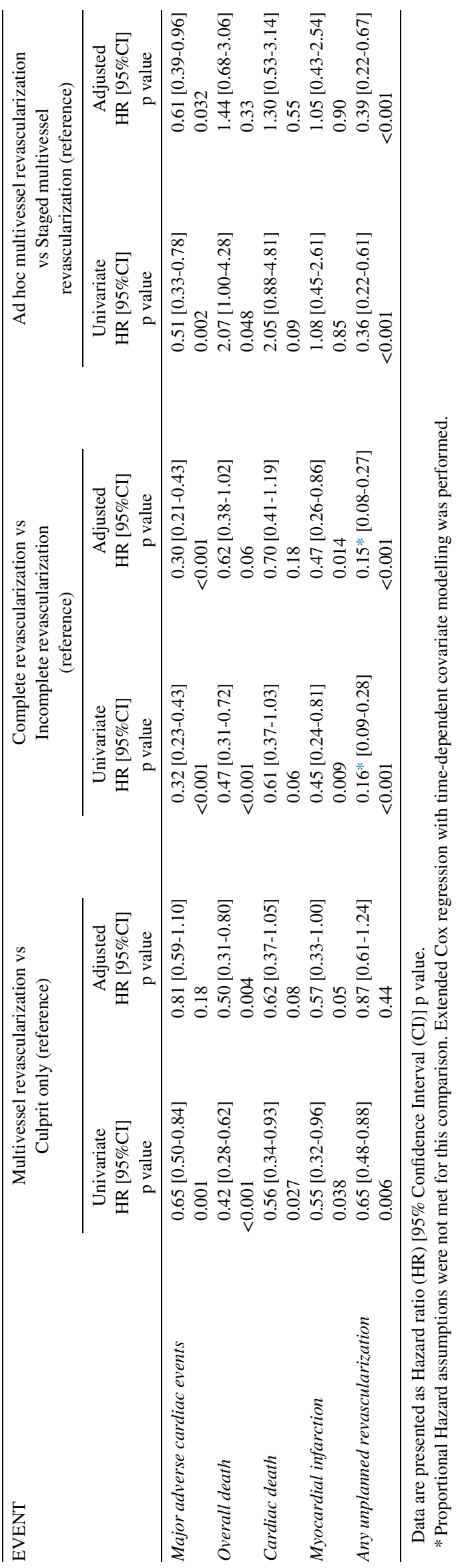


in the CvLPRIT trial. ${ }^{10}$ Lee et at, additionally reported deferred nonculprit lesions treatment resulting in a higher rate of events, in particular, ischemia-driven revascularisation ${ }^{14}$ and, Fukotomi et al, showed a lower overall mortality and MACE when the staged procedure was performed within the first 2 weeks after the index PCI instead of more than 2 weeks. This may reflect the clinical translation of the generalized coronary inflammation during Acute coronary syndrome(ACS), suggesting multiple unstable plaques in different coronary territories. ${ }^{15-17}$ Achieving prompt anatomical revascularization of nonculprit significant lesions might be responsible for the reduction in the hazard in a long-term follow-up.

In contrast with previous RCT, ${ }^{6-10,18,19}$ we found a significant reduction in the risk of all-cause mortality when MVR was performed. It is important to highlight that RCT have strict inclusion and exclusion criteria along with prespecified treatment protocols and follow-up that might not fully represent the real world clinical practice. Of note, one of the main inclusion criteria shared by those RCT was the clear indication and feasibility for a complete revascularization through a percutaneous approach at the operator's discretion, in addition, only patients with successful PCI of the culprit artery were included, possibly selecting a less high-risk or complex population and excluding $\mathrm{CABG}$ as part of the MVR treatment strategy. Moreover, none of the RCT were power to detect statistically significant differences on mortality but did show numerically lower incidence of death from any cause in the groups receiving MVR.

In line with previous reports, ${ }^{20-23}$ we observed a numerically higher mortality rate within the ad hoc group compared with the staged group. In our study, the reduction in mortality risk in the staged population might be due to a selection bias, with this group of patients representing those who survive enough time until the planned procedure was performed. Furthermore, patients who underwent ad hoc MVR might represent a sicker population; in our study, the ad hoc group was older, had more frequently history of previous MI and PCI, presented more frequently with a left coronary artery as the culprit and had a higher incidence of non-IRA complications.

Recent advances in PCI techniques and pharmacotherapy might overshadow the previous advantages found with a staged strategy on mortality, with further unplanned revascularizations being the shifting parameter in the current era. Moreover, a staged strategy was associated with a highest overall amount of contrast and number of stents, which could translate into different levels of contrast-induced nephropathy and long-term restenosis rate. ${ }^{24}$ In addition, performing a staged procedure would reasonably be associated with higher health-care costs as compared with an ad hoc strategy.

In line with previous randomized trials, ${ }^{8-10}$ our results show that complete revascularization irrespectively of the MVR strategy is associated with a lower rate of MACE, in particular, less MI and unplanned revascularizations. Finally, coronary physiology or intracoronary imaging may further address the clinical significance of nonculprit lesions. In $8.4 \%$ of staged procedures, the planned revascularization was not performed due to invasive re-evaluation of the lesions, preventing unnecessary PCI and corroborating the results of the FAME trial. ${ }^{25}$ Coronary physiology assessment of nonculprit arteries during primary PCI is feasible and safe, ${ }^{6}$ and might change the angiographic-based strategy in up to $40 \%$ of the cases ${ }^{26}$

The present investigation highlights the importance of complete revascularization in patients presenting with acute MI and MVD and although the optimal timing to perform non-IRA revascularization remains unclear, our data suggest an ad hoc strategy as the most appropriate when feasible, also considering the possible differences in terms of contrast delivered, stents usage and costs. Prospective RCT should shed further light on whether staged or ad hoc MVR should be the default strategy. The ongoing BIOVASC trial (NCT03621501) aims to randomize 1525 patients with ACS and MVD to ad hoc or staged MVR.

This is a single-center retrospective observational study. There was no independent or external monitoring of data entry. Possible case-selection bias is the main limitation of our study; non-IRA treatment strategy was at the operator's discretion, with lesion severity, suitability, and urgency for revascularization being determined by the operator at the index PCI or at the staged procedure, and so was the definition of complete revascularization. A potential Hawthorne effect could have been present in the staged cohort, accounting for some of the unplanned revascularizations occurring before the planned stage date. Our data are hypothesis-generating and require confirmation in large randomized trials because unadjusted variables may have confounded the results.

In conclusion, in patients presenting with STEMI and MVD, complete revascularization reduced the risk of MACE and ad hoc MVR appeared a reasonable strategy.

\section{Disclosures}

The authors have no conflict of interest to declare.

\section{Author's contribution}

Conception and design or analysis and interpretation of data: Maria Natalia Tovar Forero, Paola Scarparo, Matthew M. Balbi, Isabella Kardys, Nicolas M. Van Mieghem, Roberto Diletti.

Drafting of the manuscript: Maria Natalia Tovar Forero, Roberto Diletti

Critical revision of the manuscript for important intellectual content: Wijnand den Dekker, Koen Ameloot, Joost Daemen, Miguel E. Lemmert, Peter P. de Jaegere, Felix Zijlstra, Jeroen Wilschut, Kaneshka Masdjedi, Laurens van Zandvoort.

Final approval of the manuscript submitted: Maria Natalia Tovar Forero, Paola Scarparo, Wijnand den Dekker, Matthew M. Balbi, Kaneshka Masdjedi, Laurens van Zandvoort, BS Isabella Kardys, Koen Ameloot, Joost Daemen, Miguel E. Lemmert, Jeroen Wilschut, Peter P. de Jaegere, Felix Zijlstra, Nicolas M. Van Mieghem, Roberto Diletti.

\section{Supplementary materials}

Supplementary material associated with this article can be found in the online version at https://doi.org/10.1016/j. amjcard.2020.01.050. 
1. Widimsky P, Wijns W, Fajadet J, de Belder M, Knot J, Aaberge L, Andrikopoulos G, Baz JA, Betriu A, Claeys M, Danchin N, Djambazov S, Erne P, Hartikainen J, Huber K, Kala P, Klinceva M, Kristensen SD, Ludman P, Ferre JM, Merkely B, Milicic D, Morais J, Noc M, Opolski G, Ostojic M, Radovanovic D, De Servi S, Stenestrand U, Studencan M, Tubaro M, Vasiljevic Z, Weidinger F, Witkowski A, Zeymer U, European Association for Percutaneous Cardiovascular I. Reperfusion therapy for ST elevation acute myocardial infarction in Europe: description of the current situation in 30 countries. Eur Heart J 2010;31:943-957.

2. Keeley EC, Boura JA, Grines CL. Primary angioplasty versus intravenous thrombolytic therapy for acute myocardial infarction: a quantitative review of 23 randomised trials. Lancet 2003;361:13-20.

3. Muller DW, Topol EJ, Ellis SG, Sigmon KN, Lee K, Califf RM. Multivessel coronary artery disease: a key predictor of short-term prognosis after reperfusion therapy for acute myocardial infarction. Thrombolysis and Angioplasty in Myocardial Infarction (TAMI) Study Group. Am Heart J 1991;121:1042-1049.

4. Park DW, Clare RM, Schulte PJ, Pieper KS, Shaw LK, Califf RM, Ohman EM, Van de Werf F, Hirji S, Harrington RA, Armstrong PW, Granger CB, Jeong MH, Patel MR. Extent, location, and clinical significance of non-infarct-related coronary artery disease among patients with ST-elevation myocardial infarction. JAMA 2014;312:2019-2027.

5. Sorajja P, Gersh BJ, Cox DA, McLaughlin MG, Zimetbaum P, Costantini C, Stuckey T, Tcheng JE, Mehran R, Lansky AJ, Grines CL, Stone GW. Impact of multivessel disease on reperfusion success and clinical outcomes in patients undergoing primary percutaneous coronary intervention for acute myocardial infarction. Eur Heart J 2007;28:1709-1716.

6. Smits PC, Abdel-Wahab M, Neumann FJ, Boxma-de Klerk BM, Lunde K, Schotborgh CE, Piroth Z, Horak D, Wlodarczak A, Ong PJ, Hambrecht R, Angeras O, Richardt G, Omerovic E, Compare-Acute I. Fractional flow reserve-guided multivessel angioplasty in myocardial infarction. N Engl J Med 2017:376:1234-1244.

7. Wald DS, Morris JK, Wald NJ, Chase AJ, Edwards RJ, Hughes LO, Berry C, Oldroyd KG, Investigators P. Randomized trial of preventive angioplasty in myocardial infarction. N Engl J Med 2013;369: $1115-1123$.

8. Engstrom T, Kelbaek H, Helqvist S, Hofsten DE, Klovgaard L, Holmvang L, Jorgensen E, Pedersen F, Saunamaki K, Clemmensen P, De Backer O, Ravkilde J, Tilsted HH, Villadsen AB, Aaroe J, Jensen SE, Raungaard B, Kober L, Investigators D-P. Complete revascularisation versus treatment of the culprit lesion only in patients with ST-segment elevation myocardial infarction and multivessel disease (DANAMI-3PRIMULTI): an open-label, randomised controlled trial. Lancet 2015;386:665-671.

9. Mehta SR, Wood DA, Storey RF, Mehran R, Bainey KR, Nguyen H, Meeks B, Di Pasquale G, Lopez-Sendon J, Faxon DP, Mauri L, Rao SV, Feldman L, Steg PG, Avezum A, Sheth T, Pinilla-Echeverri N, Moreno R, Campo G, Wrigley B, Kedev S, Sutton A, Oliver R, Rodes-Cabau J, Stankovic G, Welsh R, Lavi S, Cantor WJ, Wang J, Nakamya J, Bangdiwala SI, Cairns JA, Committee CTS, Investigators. Complete revascularization with multivessel PCI for myocardial infarction. N Engl J Med 2019;381:1411-1421.

10. Gershlick AH, Khan JN, Kelly DJ, Greenwood JP, Sasikaran T, Curzen N, Blackman DJ, Dalby M, Fairbrother KL, Banya W, Wang D, Flather M, Hetherington SL, Kelion AD, Talwar S, Gunning M, Hall R, Swanton H, McCann GP. Randomized trial of complete versus lesion-only revascularization in patients undergoing primary percutaneous coronary intervention for STEMI and multivessel disease: the CvLPRIT trial. J Am Coll Cardiol 2015;65:963-972.

11. Ibanez B, James S, Agewall S, Antunes MJ, Bucciarelli-Ducci C, Bueno H, Caforio ALP, Crea F, Goudevenos JA, Halvorsen S, Hindricks G, Kastrati A, Lenzen MJ, Prescott E, Roffi M, Valgimigli M, Varenhorst C, Vranckx P, Widimsky P, Group ESCSD. 2017 ESC Guidelines for the management of acute myocardial infarction in patients presenting with ST-segment elevation: the Task Force for the management of acute myocardial infarction in patients presenting with ST-segment elevation of the European Society of Cardiology (ESC). Eur Heart J 2018;39:119-177.

12. Garcia-Garcia HM, McFadden EP, Farb A, Mehran R, Stone GW, Spertus J, Onuma Y, Morel MA, van Es GA, Zuckerman B, Fearon WF, Taggart D, Kappetein AP, Krucoff MW, Vranckx P, Windecker S, Cutlip D, Serruys PW, Academic Research C. Standardized end point definitions for coronary intervention trials: the academic research consortium-2 consensus document. Circulation 2018:137:2635-2650.

13. Thygesen K, Alpert JS, Jaffe AS, Chaitman BR, Bax JJ, Morrow DA, White HD, Executive Group on behalf of the Joint European Society of Cardiology /American College of Cardiology /American Heart Association /World Heart Federation Task Force for the Universal Definition of Myocardial I. Fourth universal definition of myocardial infarction (2018). J Am Coll Cardiol 2018;72:2231-2264.

14. Lee JM, Choi KH, Koo BK, Shin ES, Nam CW, Doh JH, Hwang D, Park J, Zhang J, Lim HS, Yoon MH, Tahk SJ. Prognosis of deferred non-culprit lesions according to fractional flow reserve in patients with acute coronary syndrome. EuroIntervention 2017;13:e1112-e1119.

15. Kubo T, Imanishi T, Kashiwagi M, Ikejima H, Tsujioka H, Kuroi A, Ishibashi K, Komukai K, Tanimoto T, Ino Y, Kitabata H, Takarada S, Tanaka A, Mizukoshi M, Akasaka T. Multiple coronary lesion instability in patients with acute myocardial infarction as determined by optical coherence tomography. Am J Cardiol 2010;105:318-322.

16. Hong MK, Mintz GS, Lee CW, Lee JW, Park JH, Park DW, Lee SW, Kim YH, Cheong SS, Kim JJ, Park SW, Park SJ. A three-vessel virtual histology intravascular ultrasound analysis of frequency and distribution of thin-cap fibroatheromas in patients with acute coronary syndrome or stable angina pectoris. Am J Cardiol 2008;101:568-572.

17. Asakura M, Ueda Y, Yamaguchi O, Adachi T, Hirayama A, Hori M, Kodama K. Extensive development of vulnerable plaques as a pancoronary process in patients with myocardial infarction: an angioscopic study. J Am Coll Cardiol 2001;37:1284-1288.

18. Bangalore S, Toklu B, Wetterslev J. Complete versus culprit-only revascularization for ST-segment-elevation myocardial infarction and multivessel disease: a meta-analysis and trial sequential analysis of randomized trials. Circ Cardiovasc Interv 2015;8:e02142. https:// doi.org/10.1161/CIRCINTERVENTIONS.114.002142.

19. Elgendy IY, Mahmoud AN, Kumbhani DJ, Bhatt DL, Bavry AA. Complete or culprit-only revascularization for patients with multivessel coronary artery disease undergoing percutaneous coronary intervention: a pairwise and network meta-analysis of randomized trials JACC Cardiovasc Interv 2017;10:315-324.

20. Kornowski R, Mehran R, Dangas G, Nikolsky E, Assali A, Claessen BE, Gersh BJ, Wong SC, Witzenbichler B, Guagliumi G, Dudek D, Fahy M, Lansky AJ, Stone GW, Investigators H-AT. Prognostic impact of staged versus "'one-time" multivessel percutaneous intervention in acute myocardial infarction: analysis from the HORIZONS-AMI (harmonizing outcomes with revascularization and stents in acute myocardial infarction) trial. J Am Coll Cardiol 2011:58:704-711.

21. Manari A, Varani E, Guastaroba P, Menozzi M, Valgimigli M, Menozzi A, Magnavacchi P, Franco N, Marzocchi A, Casella G. Long-term outcome in patients with ST segment elevation myocardial infarction and multivessel disease treated with culprit-only, immediate, or staged multivessel percutaneous revascularization strategies: insights from the REAL registry. Catheter Cardiovasc Interv 2014;84:912-922.

22. Iqbal MB, Nadra IJ, Ding L, Fung A, Aymong E, Chan AW, Hodge S, Della Siega A, Robinson SD, British Columbia Cardiac Registry I. Culprit vessel versus multivessel versus in-hospital staged intervention for patients with ST-segment elevation myocardial infarction and multivessel disease: stratified analyses in high-risk patient groups and anatomic subsets of nonculprit disease. JACC Cardiovasc Interv 2017;10:11-23.

23. Jensen LO, Thayssen P, Farkas DK, Hougaard M, Terkelsen CJ, Tilsted HH, Maeng M, Junker A, Lassen JF, Horvath-Puho E, Sorensen HT, Thuesen L. Culprit only or multivessel percutaneous coronary interventions in patients with ST-segment elevation myocardial infarction and multivessel disease. EuroIntervention 2012;8:456-464.

24. Mauri L, O’Malley AJ, Cutlip DE, Ho KK, Popma JJ, Chauhan MS, Baim DS, Cohen DJ, Kuntz RE. Effects of stent length and lesion length on coronary restenosis. Am J Cardiol 2004;93:1340-1346. A1345.

25. Tonino PA, Fearon WF, De Bruyne B, Oldroyd KG, Leesar MA, Ver Lee PN, Maccarthy PA, Van't Veer M, Pijls NH. Angiographic versus functional severity of coronary artery stenoses in the FAME study fractional flow reserve versus angiography in multivessel evaluation. J Am Coll Cardiol 2010;55:2816-2821.

26. Andell P, Berntorp K, Christiansen EH, Gudmundsdottir IJ, Sandhall L, Venetsanos D, Erlinge D, Frobert O, Koul S, Reitan C, Gotberg M. Reclassification of treatment strategy with instantaneous wave-free ratio and fractional flow reserve: a substudy from the iFR-SWEDEHEART Trial. JACC Cardiovasc Interv 2018;11:2084-2094. 